\title{
Uji Daya Hambat Ekstrak Etanol Daun Inai (Lawsonia inermis L.) terhadap Pertumbuhan Staphylococcus aureus
}

\author{
Sasmiati Farach Dita*, Lidyawati, Mutiara Sampoerna \\ Akademi Farmasi YPPM Mandiri, Banda Aceh, Indonesia \\ Email: sasmiati.fd@gmail.com
}

\begin{abstract}
Abstrak-Daun inai sering dimanfaatkan sebagai obat tradisional diantaranya sebagai antibakteri. Daun inai mengandung beberapa komponen aktif diantaranya adalah fenol dan flavonoid yang bersifat sebagai antibakteri. Adapun tujuan dari penelitian ini adalah untuk mengetahui daya hambat ekstrak etanol daun inai (Lowsonia inermis L.) terhadap pertumbuhan bakteri Staphyloccocus aureus. Penelitian ini telah dilakukan menggunakan metode deskriptif. Pada penelitian ini ekstrak etanol daun inai dibuat dengan metode maserasi. Pengujian ekstrak etanol daun inai terhadap bakteri Staphylococcus aureus dilakukan pada media Nutrient Agar (NA) dan menggunakan metode sumuran dengan 3 konsentrasi ekstrak yaitu konsentrasi $40 \%, 50 \%$ dan $90 \%$, kontrol negatif digunakan aquadest dengan masing-masing 3 kali pengulangan. Hasil penelitian ini menunjukkan diameter zona hambat ekstrak daun inai pada konsentrasi $40 \%$ dihasilkan sebesar $21.29 \mathrm{~mm}$, pada konsentrasi 50\% sebesar $23.1 \mathrm{~mm}$ dan pada konsentrasi $90 \%$ sebesar $24.4 \mathrm{~mm}$, pada kontrol positif sebesar $27.93 \mathrm{~mm}$ dan kontrol negatif akuades tidak memberikan zona hambat. Zona hambat,untuk seluruh konsentrasi termasuk kategori daya hambat yang kuat.
\end{abstract}

Kata Kunci: Ekstrak Etanol Daun Inai (Lowsonia Inermis L); Staphylococcus Aureus; Zona Hambat

\begin{abstract}
Henna leaves are often used as traditional medicine, including as an antibacterial. Henna leaves contain several active components including phenols and flavonoids which act as antibacterial. The purpose of this study was to determine antibacterial activity of ethanol extract of henna leaves (Lowsonia inermis L.) against Staphyloccocus aureus. This research was conducted using descriptive method. In this study, ethanol extract of henna leaf was made by maceration method. Ethanol extract of henna leaves was tested against Staphylococcus aureus on Nutrient Agar (NA) medium using well diffusion method with 3 extract concentrations, namely $40 \%, 50 \%$ and $90 \%$, tetracycline as positive control and aquadest as negative control with 3 repetitions each. The results of this study showed that inhibition zone diameter of henna leaves extract at a concentration of $40 \%$ was $21.29 \mathrm{~mm}$, at a concentration of $50 \%$ was $23.1 \mathrm{~mm}$ and at a concentration of $90 \%$ was $24.4 \mathrm{~mm}$, positive control was $27.93 \mathrm{~mm}$ and negative control did not show inhibition zone. The inhibition zone for all concentrations belongs to strong inhibition category.
\end{abstract}

Keywords: Ethanol Extract of Henna Leaves (Lowsonia Inermis L); Staphylococcus Aureus; Inhibition Zone

\section{PENDAHULUAN}

Tanaman herbal masih merupakan pilihan utama yang digunakan dalam pengobatan di beberapa belahan dunia. Meskipun pemulihannya lambat, namun tanaman herbal memiliki efek samping yang lebih rendah. Penyakit yang sering diobati dengan tanaman herbal salah satunya adalah infeksi yang disebabkan oleh bakteri, salah satu bakteri yang dapat menyebabkan penyakit antara lain Staphylococcus aureus (Pratiwi et al., 2014).

Bakteri S. aureus adalah bakteri gram positif berbentuk bulat yang merupakan bakteri patogen bagi manusia. Bakteri S. aureus juga dapat menginfeksi jaringan atau alat tubuh lain yang menyebabkan timbulnya penyakit dengan tanda-tanda yang khas seperti nekrosis, peradangan dan pembentukan abses serta dapat menyebabkan berbagai macam infeksi seperti pada jerawat, bisul, atau nanah. Bakteri S. aureus memiliki kemampuan berkembangbiak dan menyebar luas dalam jaringan tubuh serta adanya beberapa zat ekstraseluler yang dapat diproduksi (Tuntu, 2016).

Menurut Razak et al., (2013), S. aureus diperkirakan 20 - 75\% ditemukan pada saluran pernapasan atas, muka, tangan, rambut dan vagina. Penyakit infeksi yang disebabkan oleh bakteri S. aureus secara medis dapat disembuhkan dengan obat-obatan seperti penisilin, kloksasilin, dikloksasilin, eritromisin, nafsilin dan oksasilin. Selain penggunaan obat-obatan kimia dan medis, infeksi yang diakibatkan oleh bakteri S. aureus ini dapat juga

Salah satu tumbuhan yang berkhasiat untuk pengobatan antibakteri yang disebabkan oleh bakteri S. aureus adalah Lawsonia inermis L. Tumbuhan L. inermis yang dikenal pula dengan nama Inai merupakan suatu tumbuhan berbunga, spesies tunggal dari genus Lawsonia dari famili Lythraceae. Tumbuhan ini merupakan tumbuhan asli daerah tropis dan subtropis seperti Afrika Selatan, Afrika Timur dan Utara, Asia dan Australia Utara yang secara alamiah tumbuh juga di di daerah-daerah tropis di Amerika, Mesir, India dan sebagian daerah Timur Tengah (Hairunnisa, 2015). Menurut Zubardiah et al., (2008), daun inai selain digunakan untuk mewarnai rambut dan kuku, memiliki khasiat sebagai antibakteri, antiiritan, antioksidan, antikarsinogenik, anti-inflamasi, analgetik dan antipiretik.

\section{METODOLOGI PENELITIAN}

\subsection{Alat dan Bahan}

Alat yang digunakanan adalah pipet tetes, cork borer, ose bulat, pinset, tabung reaksi, cawan porselin gelas arloji, object glass, cover glass, mistar/penggaris, petridis, lampus piritus, erlenmayer, mikropipet, beaker glass, hot plate, timbangan analitik, autoklaf, oven, inkubator, corong, penangas air, labu ukur, dan batang pengaduk. Bahan-bahan yang digunakan adalah daun inai (Lawsonia inermis L.), bakteri S. aureus, media Nutrient Agar (NA), larutan tetrasiklin, akuades, akuades pro injeksi, benang jagung, kertas ubi, etanol 70\%, $\mathrm{NaCl} \mathrm{0,9 \% ,} \mathrm{larutan} \mathrm{standar} \mathrm{Mc} \mathrm{Farland} \mathrm{0,5.}$ 


\section{Journal of Pharmaceutical and Health Research}

Vol 2, No 3, Oktober 2021, pp. 67-69

ISSN 2721-0715 (media online)

DOI 10.47065/jharma.v2i3.982

\subsection{Pembuatan Serbuk Simplisia}

Daun inai yang diambil adalah daun dewasa. Daun inai dibersihkan dari kotoran yang menempel, dengan mencuci daun inai di bawah air mengalir sampai besih, kemudian tiriskan. Setelah itu daun inai dirajang kecil-kecil, lalu dilakukan pengeringan di lemari pengering teduh selama 3 sampai 4 hari sesekali daun inai dibolak-balik. Simplisia yang telah kering dihaluskan menggunakan blender, kemudian diayak dengan ayakan mesh no. 60, setelah halus dimasukkan kedalam wadah.

\subsection{Pembuatan Ekstrak Etanol Daun Inai}

Serbuk simplisia kering daun inai ditimbang sebanyak $150 \mathrm{~g}$ kemudian ditambahkan $1500 \mathrm{ml}$ pelarut etanol $70 \%$. Selanjutnya direndam, selama 6 jam pertama diaduk sesekali lalu direndam lagi selama18 jam (tanpa diaduk). Sampel kemudian dienaptuangkan dan diambil filtrat pertama (F1). Kemudian ditambahkan $150 \mathrm{ml}$ pelarut etanol $70 \%$ pada ampas. Direndam selama 6 jam (diaduk sesekali) dilanjutkan lagi direndam selama 18 jam. Disaring dengan kain flanel, diambil filtrat kedua (F2) dan digabungkan F1 (filtrat pertama) dan F2 (filtrate kedua), kemudian didiamkan selama 1 jam. Selnajutnya dienaptuangkan dan diuapkan maserat sampai menjadi ekstrak pekat. Kemudian persen rendemen dihitung.

\subsection{Pembuatan Konsentrasi Ekstrak Daun Inai}

Konsentrasi ekstrak yang digunakan yaitu 40\%, 50\% dan 90\%. Ekstrak daun inai (L. inermis) ditimbang sebanyak $4 \mathrm{~g}$, $5 \mathrm{~g}$ dan $9 \mathrm{~g}$ untuk masing-masing konsentrasi 40\%, 50\% dan 90\%, lalu ditambahkan ke dalam larutan pengencer (DMSO) sampai $10 \mathrm{ml}$.

\subsection{Pembiakan Bakteri Uji}

Bakteri S. aureus dari Laboratorium Fundament Lab Sains Baitusallam Aceh Besar Kemudian dibiakkan kembali pada masing-masing media Nutrien Agar secara zig-zag dengan menggunakan ose steril, selanjutnya diinkubasi di dalam incubator pada suhu $37^{\circ} \mathrm{C}$ selama 24 jam.

\subsection{Pembuatan Suspensi Standar Mc Farland}

Sebanyak $0.5 \mathrm{ml}$ larutan Barium Chloride dihidrat $\left(\mathrm{BaCl}_{2} .2 \mathrm{H}_{2} \mathrm{O}\right)$ ditambahkan ke dalam $9.95 \mathrm{ml}$ Asam Sulfat $\left(\mathrm{H}_{2} \mathrm{SO}_{4}\right)$ $1 \%$ yang berada di tabung yang memakai tutup. Kemudian dikocok sampai terbentuk larutan yang keruh. Kekeruhan ini dipakai sebagai standar kekeruhan suspensi bakteri uji.

\subsection{Pembuatan Suspensi Bakteri Staphylococcus aureus}

Disiapkan tabung reaksi yang sudah disterilkan dan dimasukkan $10 \mathrm{ml} \mathrm{NaCl} \mathrm{0,9 \%} \mathrm{ke} \mathrm{dalam} \mathrm{tabung} \mathrm{reaksi.} \mathrm{Selanjutnya}$ diambil biakan bakteri $S$. aureus menggunakan ose bulat, dimasukkan kedalam tabung reaksi yang berisi $\mathrm{NaCl} 0,9 \%$ steril, dikocok kemudian bandingkan kekeruhannya dengan standar Mc Farland.

\subsection{Pengujian Daya Hambat Ekstrak Daun Inai terhadap Bakteri Staphylococcus aureus}

Suspense bakteri S. aureus diambil menggunakan ose steril lalu dioleskan keseluruh permukaan media NA. Kemudian dibuat lubang sumuran menggunakan cork borer sebanyak 5 lubang. Sebanyak $15 \mu 1$ ekstrak etanol daun inai dengan konstrasi 40\%, 50\% dan 90\% diambil dan dimasukkan ke masing-masing lubang sumuran. Sampel kemudian diinkubasi pada suhu $37^{\circ} \mathrm{C}$ selama 24 jam dan dilakukan tiga kali pengulangan. Akuades digunakan sebagai kontrol negatif dan tetrasiklin sebagai kontrol positif. (Prayoga, 2013). Perhitungan luas zona hambat yang diamati pada media, zona hambat dapat dikategorikan sebagai berikut, untuk diameter $>20 \mathrm{~mm}$ dikategorikan sangat kuat, 11-20 mm dikategorikan kuat, 6-10 mm dikategorikan sedang dan <5 mm dikategorikan lemah (Susanto et al., 2012).

\section{HASIL DAN PEMBAHASAN}

\subsection{Hasil}

Hasill pengujian daya hambat ekstrak etanol daun inai (Lowsonia inermis L.) terhadap pertumbuhan bakteri Staphylococcus aureus dengan metode sumuran dan menggunakan konsentrasi ekstrak 40\%, 50\% dan 90\% dengan kontrol positif antibiotik tetrasiklin dan kontrol negatif akuades menunjukkan bahwa semua konsentrasi dapat menghambat pertumbuhan $S$. aureus. Diameter zona hambat yang terbentuk dapat dilihat pada tabel di bawah ini.

Tabel 1. Diameter Zona Hambat (Mm) Pada Media Pertumbuhan Bakteri S. Aureus.

\begin{tabular}{|c|c|c|c|c|c|c|}
\hline \multirow{2}{*}{ No. } & \multirow{2}{*}{ Zat Uji } & \multicolumn{3}{|c|}{ Diameter Zona Hambat } & \multirow{2}{*}{ Diameter Rata-rata } & \multirow{2}{*}{ Katagori Daya Hambat } \\
\hline & & P1 & $\mathrm{P} 2$ & P3 & & \\
\hline 1 & Konsentrasi $40 \%$ & 21.33 & 21.09 & 21.45 & 21.29 & Kuat \\
\hline 2 & Konsentrasi $50 \%$ & 22.49 & 23.08 & 23.73 & 23.1 & Kuat \\
\hline 3 & Konsentrasi 90\% & 24.29 & 24.72 & 24.19 & 24.4 & Kuat \\
\hline 4 & Tetrasiklin (kontrol positif) & 27.04 & 26.88 & 29.87 & 27.93 & Kuat \\
\hline
\end{tabular}




\subsection{Pembahasan}

Proses ekstraksi daun inai dilakukan secara maserasi. Maserasi adalah cara penarikan simplisia dengan merendam simplisia tersebut dalam cairan penyari pada suhu biasa ataupun memakai pemanasan. Berat daun inai sebelum dikeringkan adalah $241 \mathrm{gr}$, sedangkan berat serbuk simplisia setelah dikeringkan dan haluskan adalah 184 gr.

Penelitian uji daya hambat ekstrak etanol daun inai (Lawsonia inermis L.) terhadap pertumbuhan bakteri Staphylococcus aureus dilakukan dengan berbagai konsentrasi yaitu 40, 50\% dan 90\% serta menggunakan tetrasiklin sebagai kontrol positif dan akudes sebagai kontrol negatif. Pengukuran zona hambat dilakukan dengan melihat zona hambat disekitar sumur dan diukur menggunakan mistar dalam satuan mm pada permukaan bagian bawah petridisk. Hasil pengamatan menunjukkan bahwa pada konsentrasi $40 \%$ pengulangan pertama didapatkan zona hambat sebesar 21,33 $\mathrm{mm}$, pengulangan kedua sebesar 21,09 $\mathrm{mm}$ dan pengulangan ketiga sebesar 21,45 mm sehingga diperoleh diameter ratarata sebesar 21,29 mm. Pada konsentrasi 50\% pengulangan pertama didapatkan zona hambat sebesar 22,49 mm, pengulangan kedua sebesar 23,08 $\mathrm{mm}$ dan pengulangan ketiga 23,73 $\mathrm{mm}$ sehingga diperoleh hasil diameter rata-rata sebesar 23,1 mm. Pada konsentrasi 90\% pengulangan pertama didapatkan zona hambat sebesar 24,29 mm, pada pengulangan kedua didapatkan zona hambat sebesar 24,72 mm dan pengulangan ketiga 24,19 mm sehingga diperoleh hasil diameter rata-rata sebesar 24,4 mm. Hasil pengamatan pada kontrol positif (tetrasiklin) pada pengulangan pertama didapatkan 27,04 mm, pengulangan kedua sebesar 26,88 mm, pengulangan ketiga sebesar 29.87 mm sehingga diperoleh hasil rata-rata $27.93 \mathrm{~mm}$. Hasil pengamatan kontrol negatif (akuades) pada pengulangan pertama sampai ketiga tidak menunjukkan adanya zona hambat yang terbentuk.

Ketiga konsentrasi yang diuji menunjukkan bahwa ketiga konsentrasi memiliki kategori daya hambat yang kuat. Konsentrasi ekstrak etanol daun inai yang menunjukkan hasil zona hambat dari yang paling tinggi hingga yang paling rendah yaitu konsentrasi $90 \%, 50 \%$ dan $40 \%$. Kemampuan ekstrak daun inai yang dapat menghambat pertumbuhan $S$. aureus ini mungkin disebabkan oleh kandungan senyawa fitokimia yang aktif, seperti alkaloid, glikosida, flavonoid, fenol, dan saponin. Fenol dan flavonoid merupakan senyawa aktif yang paling banyak ditemukan (Hairunnisa, 2015). flavonoid bekerja dengan cara menghambat sintesis asam nukleat, mengahambat fungsi membran sel dan menghambat metabolisme energi pada bakteri. (Umarudin et al., 2018).

Penelitian sebelumnya yang dilakukan oleh Hairunnisa (2015) melakukan penelitian dengan metode difusi cakram dengan menggunakan ekstrak etanol daun inai dengan konsentrasi 60\%, 70\%, 80\% dan 90\%. Pada konsentrasi 60\% didapatkan zona hambat sebesar 18.7, pada konsentrasi 70\% didapatkan zona hambat sebesar $19.57 \mathrm{~mm}$, pada konsentrasi 80\% didapatkan hasil 22.26 dan konsentrasi 90\% didapat sebesar $15.26 \mathrm{~mm}$. Berdasarkan hasil penelitian tersebut, dapat dilihat bahwa penggunaan metode difusi agar sumur menghasilkan aktifitas penghambatan yang lebih besar dibandingkan dengan metode difusi cakram.

\section{KESIMPULAN}

Dari hasil penelitian ini dapat disimpulkan bahwa ekstrak etanol daun inai (Lawsonia inermis L.) dapat menghambat pertumbuhan bakteri Staphylococcis aureus dengan menggunakan metode difusi agar sumur. Semua konsentrasi yang diuji membentuk zona hambat yang termasuk dalam kategori daya hambat yang kuat.

\section{DAFTAR PUSTAKA}

Hairunnisa. (2015). Uji Daya Hambat Ekstrak Daun Inai (Lawsonia inermis L.) terhadap Pertumbuhan Staphylococcus aureus. Tesis. Palangkaraya: IAIN Palangka Raya.

Pratiwi, Novia, D. A., Yuliani, R. (2014). Aktivitas Antibakteri Ekstrak Etanol Daun Pacar Kuku (Lawsonia Inermis L.) dan Bioautografi terhadap Bacillus Subtilis dan Shigella Sonnei. Tesis. Surakarta: Universitas Muhammadiyah Surakarta.

Prayoga, E. (2013). Perbandingan Efek Ekstrak Daun Sirih Hijau (Piper betle L.) Dengan Metode Difusi Disk dan Sumuran terhadap Bakteri Staphylococcus aureus. Skripsi. Jakarta: Universitas Islam Negri Syarif Hidayatullah.

Razak, A., Djamal, A., Revilla G. 2013. Uji Daya Hambat Air Perasan Buah Jeruk Nipis (Citrus aurantifolia s.) terhadap Pertumbuhan Bakteri Staphylococcus aureus secara In Vitro. Jurnal Kesehatan Andalas. 2(1): 5-8.

Susanto D., Sudrajat dan Ruga, R. 2012. Studi Kandungan Bahan Aktif tumbuhan Meranti Merah (Shorea leprosula Miq) sebagai Sumber Senyawa Antibakteri. Mulawarmnan Scientifie. 11(2):181-190.

Tuntun, M. (2016). Uji Efektivitas Ekstrak Daun Pepaya (Carica papaya L.) terhadap Pertumbuhan Bakteri Escherichia coli dan Staphylococcus aureus. Jurnal Kesehatan. 7(3): 497-502.

Umarudin, Rinda Y, S, Ballighul Fal, Syukrianto. (2018). Efektivitas Daya Hambat Ekstrak Etanol 96\% Bonggol Nanas (Ananas comosus L.) terhadap Pertumbuhan Bakteri Staphylococcus aureus. Jurnal of Pharmacy and Science. 3(2): 32-36.

Zubardiah, L., Dewi, N. M., \& Auerkari, E. I. (2008). Khasiat Daun Lowsonia inermis L. Sebagai Obat Tradisional Antibakteri. Jurnal Kesehatan. 19-22 